\title{
The role of phonemes and syllables in the perceived similarity of speech sounds for children
}

\author{
AMANDA C. WALLEY \\ University of Toronto, Toronto, Ontario, Canada \\ LINDA B. SMITH \\ Indiana University, Bloomington, Indiana \\ and \\ PETER W. JUSCZYK \\ University of Oregon, Eugene, Oregon
}

\begin{abstract}
In two experiments, we investigated the factors that influence the perceived similarity of speech sounds at two developmental levels. Kindergartners and second graders were asked to classify nonsense words, which were related by syllable and phoneme correspondences. The results support the existence of a developmental trend toward increased attention to individual phonemic segments. Moreover, one significant factor in determining the perceived similarity of speech sounds appears to be the position of the component correspondences; attention to the beginning of utterances may have developmental priority. An unexpected finding was that the linguistic status of the unit involved in a correspondence (whether it was a syllable or a phoneme) did not seem particularly important. Apparently, the factors which contribute to the perceived similarity of speech sounds in the classification task are not identical to those which underlie performance in explicit segmentation and manipulation tasks, since in the latter sort of task, syllables are more accessible than phonemes for young children. The present task may tap a level of processing that is closer to the one entailed in word recognition and lexical access.
\end{abstract}

A large set of empirical studies indicates that young children have difficulty in attending to the phonemic segments of speech. For example, children under 6 years of age are poor at judging the number of phonemic segments in spoken words and nonsense words (Elkonin, 1973; I. Y. Liberman, Shankweiler, Fischer, \& Carter, 1974; Rozin, Bressman, \& Taft, 1974; Treiman \& Baron, 1981), at making same-different judgments about phonemic segments (Calfee, Chapman, \& Venezky, 1972; Jusczyk, 1977; Savin, 1972), and at rearranging and deleting phonemic segments (Bruce, 1964; Rosner \& Simon, 1971). The ability to segment speech into phonemes appears critically related to learning to read an alphabetic orthogra-

\footnotetext{
We thank the children and teachers at Grandview Elementary School for their participation and cooperation in conducting this study. M. IntonsPeterson, D. B. Pisoni, and R. Treiman provided valuable comments on an earlier version of this paper. Jackie Baker, Melanie Lockyear, and Carol McCord assisted in data collection and manuscript preparation. The work reported here was supported by NSF Grants BNS 7813019 and BNS 81-09888 to the second author; by NSERC (A-0282) and NICHHD (HDNs-15795) grants to the third author; by a doctoral fellowship from the Social Sciences and Humanities Research Council of Canada and NSERC (A-1078) grant awarded to the first author; and by NIMH (MH-24027) and NIH (NS-12179) grants. Address reprint requests to A. C. Walley, Department of Psychology, University of Toronto, St. George Campus, Toronto, Ontario, Canada M5S 1 Al.
}

phy (for a review of the relevant literature, see Gleitman \& Rozin, 1977; Rozin \& Gleitman, 1977). Children who have particular difficulty in phoneme segmentation tasks have considerable difficulty in learning to read, although researchers differ in their views of the precise nature of the causal relation between these abilities (cf. I. Y. Liberman, Shankweiler, A. M. Liberman, Fowler, \& Fischer, 1977; Stanovich, Cunningham, \& Cramer, 1984; Treiman \& Baron, 1981).

One line of evidence documenting children's tendency not to attend to phonemes is children's performance in classification tasks. For example, Treiman and her associates (Treiman \& Baron, 1981; Treiman \& Breaux, 1982) found that young children attend to whole sounds, not single phonemes. Thus, 5-year-olds classify together and judge as similar the sounds / vis/ and /bez/more often than they do /bez/ and /bug/. The sounds /vis/ and /bez/, although they do not share any single phoneme, are globally alike across the whole sound or are similar overall (Singh \& Woods, 1971; Singh, Woods, \& Becker, 1972). Older children and adults, in contrast, classify /bez/ and /bug/ together, not /bez/ and /vis/. For them, an initial phonemic match is more important for classifying sounds together than is similarity across the whole sound. With development then (and perhaps learning to read), there 
is an increase in attention to the phonemic structure of speech.

The question we address in this research is whether there is a unit above the level of the phoneme, but below the level of the whole sound, to which young children can easily attend. The candidate unit is the syllable. Many investigators have suggested that syllables are perceptually more primary units than are phonemes (e.g., Aslin, Pisoni, \& Jusczyk, 1983; Bertoncini \& Mehler, 1981; Jusczyk, 1982, 1983; Mehler, Dommergues, Frauenfelder, \& Segui, 1981; Savin \& Bever, 1970; see also Foss $\&$ Swinney, 1973). Part of the motivation for these claims concerns the context-dependent manner in which phonemes are encoded in the waveform during production (e.g., Gleitman \& Rozin, 1977; A. M. Liberman, Cooper, Shankweiler, \& Studdert-Kennedy, 1967). Syllables may exhibit less contextual variability than phonemes. Furthermore, there is a distinctive peak of acoustic energy associated with the vocalic nucleus contained in all syllables (e.g., I. Y. Liberman et al., 1977). These properties may render syllables particularly isolable or separable constituents of speech for the perceptual system.

There is also suggestive developmental evidence consistent with this hypothesized "primacy" of the syllable. Young children are better at counting the number of syllables versus phonemes in spoken words and nonsense words (I. Y. Liberman et al., 1974; Treiman \& Baron, 1981). Perhaps, then, young children can and do attend to the constituents of speech sounds if those constituents are syllables. In other words, younger children's perception of speech may be more global or holistic than other children's in that they segment speech into larger units, namely syllables, rather than phonemes. Notice that Treiman's (1980) findings that young children classify by overall similarity is consistent with the view that syllables are the principle constituents in children's perception of speech. In her studies, the speech sounds employed were single whole syllables and the items grouped together by young children were the two most similar syllables. However, no study has yet examined children's free classifications of multisyllabic sounds; thus, there is no direct evidence showing that young children classify by syllable correspondences more readily than they do by phoneme correspondences.

Accordingly, in the following two experiments, we examined children's spontaneous classifications of twosyllable sounds. We asked young children, who have considerable difficulty in finding single phoneme correspondences, and older children, who are better able to find such correspondences, to classify speech sounds. Our question was whether children would be able to classify together sounds that share whole syllables before they are able to consistently group sounds that share single phonemes or several phonemes not conjoined within a syllable. An affirmative answer would support a developmental trend from the perception of syllable correspondences between speech sounds to the perception of phoneme correspondences.

\section{EXPERIMENT 1}

A child who is asked whether the target item /no/ is most like the sound $/ \mathrm{nu} /$ or the sound $/ \mathrm{ba} /$ should answer $/ \mathrm{nu} /$. The sounds $/ \mathrm{n} \approx /$ and $/ \mathrm{nu} /$ are identical in their initial phonemes, whereas $/ \mathrm{n} \sigma /$ and $/ \mathrm{ba} /$ are different in all components. Despite the apparent simplicity of this classification task, it is not simple for 4- and 5-year-olds; they often respond randomly, presumably because, as whole sounds, $/ \mathrm{n} \approx /, / \mathrm{nu} /$, and $/ \mathrm{ba} /$ are simply all very different (Rozin \& Gleitman, 1977; Walley, Smith, \& Jusczyk, 1980). In this experiment, we asked whether young children would consistently classify more complex sounds if the correct classification were based on a whole-syllable correspondence and not on a single-phoneme correspondence. For example, if children were asked whether the target /nu-tae/ were most like the standard /nu-li/ or /bago/, would they answer correctly, easily noting the whole syllable correspondence between /nu-tae/ and /nu-li/?

In the experiment, children first learned one exemplar (the standard) from each of two categories. The child was then presented with novel test items and for each test item was asked with which standard it belonged (to which it was most similar). Table 1 shows one of the stimulus sets employed. The two standards in this set, /nu-li/ and /bago/, differ considerably (according to adult similarity ratings; Singh \& Woods, 1971; Singh et al., 1972) on each same-position phoneme. The test items are of three kinds and share either the first $\mathrm{C}$ (consonant), $\mathrm{CV}$ (consonant and vowel), or CVC with one standard and differ maximally from that standard on all remaining phonemes and from the other standard on all phonemes. Thus, each test item is maximally similar to one and only one standard, but the three test-item types differ in the extent to which they share constituents with one standard.

We expected children to perform well on all three item types $\left(\mathrm{C}_{\perp}, \mathrm{CV}_{\perp}, \mathrm{CVC}_{-}\right)$if they recognize and make use of single-phoneme correspondences between two speech sounds. We expected that this pattern of performance would be characteristic of second graders, but not of kindergartners; previous research has shown that older children are better able to isolate individual phonemes and make classifications on this basis than are younger children (e.g., I. Y. Liberman et al., 1974; Treiman \& Baron, 1981). Our question was whether the kindergartners, who should fail to consistently classify singlephoneme $\mathrm{C} \_$items, would nonetheless correctly clas-

Table 1

Sample Stimulus Set from Experiment 1

\begin{tabular}{|c|c|c|}
\hline \multirow{2}{*}{$\begin{array}{c}\text { Test-Item } \\
\text { Type }\end{array}$} & \multicolumn{2}{|c|}{ Standards } \\
\hline & nuli & bago \\
\hline $\mathrm{C}$ & $\begin{array}{l}\text { ñ } \sigma \text { tae } \\
\text { naeš }\end{array}$ & $\begin{array}{l}\text { botace } \\
\text { baešz }\end{array}$ \\
\hline $\mathrm{CV}_{-}$ & $\begin{array}{l}\text { nutzr } \\
\text { nušae }\end{array}$ & $\begin{array}{l}\text { batox } \\
\text { bašae }\end{array}$ \\
\hline $\mathrm{CVC}_{-}$ & $\begin{array}{l}\text { nulae } \\
\text { nula } \sigma\end{array}$ & $\begin{array}{l}\text { bagae } \\
\text { bagr }\end{array}$ \\
\hline
\end{tabular}


sify the $\mathrm{CV}$ _ items which share the whole first syllable with one standard. If, in contrast, whole-syllable correspondences are not particularly salient, then kindergartners might not perform well on any item, or perhaps might perform well only on the $\mathrm{CVC}_{-}$items which are very much like one standard (they share three of the four phonemes with one standard).

In brief, the critical question is how well younger children classify $\mathrm{CV}_{\text {_ }}$ items (assuming, as previous research would suggest, that they perform poorly for $\mathrm{C} \_$__ items). Of course, correct classification of $\mathrm{CV}_{\text {_ }}$ items might occur even if the syllable has no special status-if, for example, two phoneme correspondences are sufficient, but one is not. However, the point we stress is that correct classification of $\mathrm{CV}_{\text {_ }}$ items should be obtained if the syllable is an easily used unit of speech for young children. Failure to find such a result would be quite inconsistent with the hypothesis of a developmentally special status of the syllable.

\section{Method}

Subjects. Twelve kindergartners (mean age $=5$ years, 11 months; range $=5,7$ to 6,$1 ; 6$ males, 6 females) and 12 second graders (mean age $=7,10 ;$ range $=7,6$ to 8,$3 ; 8$ males, 4 females), who were enrolled in a middle-class Indiana elementary school, participated in the experiment. All subjects met the criterion of 10 correct consecutive responses in training and $67 \%$ correct classifications of the standards in testing. No gross speech or hearing disorder was reported for any child by parents at the time of testing, and all subjects were native speakers of English.

Stimuli and design. A pool of six consonants ( $/ \mathrm{b}, \mathrm{g}, \mathrm{l}, \mathrm{n}, \mathrm{t}, \breve{\mathrm{s}} /)$, each of which differed from one another by approximately the same amount, according to adult perceptual similarity ratings collected by Singh et al. (1972), was chosen for this experiment. Similarly, a pool of six vowels $(/ \mathrm{i}, \mathrm{ae}, \mathrm{a}, \boldsymbol{\gamma}, \mathrm{o}, \mathrm{u} / \mathrm{)}$ was selected, such that the vowels were, in accordance with perceptual similarity estimates obtained by Singh and Woods (1971), approximately as dissimilar from one another as were the consonants. Two stimulus sets were then constructed from these consonant and vowel pools. Within a stimulus set, two standards (two CV-CV stimuli) were constructed by drawing from the consonant and vowel pools without replacement. For example, the standards in one test set were /nu-li/ and /ba-go/. Test items (also CV-CV stimuli) were then chosen such that they shared either the first $\mathrm{C}, \mathrm{CV}$, or CVC with one, and only one, of the two standards; the remainder of a given test item consisted of a combination of items left in the consonant and vowel pools. Within a stimulus set, two different test items were related to either of the standards in one of the ways specified above (e.g., shared the initial C). Table 1 shows one of the stimulus sets.

The stimuli were produced in citation form by a phonetically sophisticated female speaker (Experimenter 1), who maintained approximately equal stress assignment between the two syllables of a given stimulus. The stimuli were recorded inside a soundattenuated IAC booth using a high-quality microphone and Ampex (Model AG,500) tape recorder. Two audiotapes were prepared for each stimulus set. Each tape consisted initially of a randomized sequence of the standards for a particular stimulus set. This sequence was followed by the test items in the set. Each test item occurred twice; thus, there were 8 test trials for each of the three item types. These 24 test trials occurred in random order, with the restrictions that one of the standards intervened between every 4 test items (i.e., each training stimulus occurred three times within the test block) and that the order of standard presentation was alternated. Thus, a test block consisted of 30 stimulus presentations. An adult listener, naive as to the purpose of the experiment, was asked to segment the materials on each tape by making a vertical slash on prepared transcriptions wherever she perceived a syllable boundary. Ninetyseven percent of her responses were consistent with the intended CV-CV structure of the stimuli.

Subjects were randomly assigned to one of the stimulus sets, and the assignment of puppets to standards within a set was counterbalanced.

Procedure. Each subject was tested individually in a single session lasting no more than $\mathbf{4 5} \mathrm{min}$. The session included the auditory classification task (pretraining and testing) and, in the case of kindergartners, an assessment of beginning reading ability (see below).

The experimental session began with pretraining. The subject was seated at a table facing two puppets. Experimenter 1 sat facing the child and Experimenter 2 to one side. The child was informed that each of the two puppets made a "special" sound that the child was to learn. The child was asked to pat the correct puppet on the head whenever he/she heard the puppet's sound. The standards (and test items in testing) were presented to subjects by audiotape on a portable Uher (Model 4200) tape recorder at a comfortable listening level. Experimenter 2 operated the tape recorder and stopped the tape whenever this was necessary for the child to complete his/her response on a trial. Experimenter 1 recorded each response from the child and informed him/her whether or not he/she was correct. After meeting the criterion of 10 correct consecutive responses on a maximum of $\mathbf{4 5}$ trials, the testing phase of the task was initiated.

In testing, the child was told that he/she was going to hear several additional different sounds made by the puppets. The child was told that each new sound (the test items) was made by one and only one of the puppets. The child was to indicate with which of the original sounds each new sound belonged or to which it was most similar by patting one of the puppets on the head. Experimenter 2 operated the tape recorder, presenting one stimulus at a time. No feedback, only general encouragement, was given for the child's responses to test items, since we wished to examine free classification performance. However, the child was given feedback on the trials for training items that were interspersed between the test items to ensure intact memory for these items and thus an adequate basis for making similarity judgments. A criterion of $67 \%$ correct responding on the standards in testing was established for inclusion in the data analysis.

The final phase of the session for kindergartners consisted of an assessment of beginning reading ability. Given previous findings concerning the relationship between phonemic analysis skills, the acquisition of spelling-sound rules, and reading success (see Rozin \& Gleitman, 1977; Treiman, 1980), we were interested in obtaining some measure of reading ability in the kindergartners. Of course, superior performance by second graders relative to kindergartners in the classification task could be the result of either age-related changes in speech processing (including greater experience with this activity) or reading experience (or both factors); however, in the event that kindergartners' classification performance in the present study was similar to second graders', we wanted some indication of the extent to which this might be due to reading experience and/or ability versus preexisting analysis skills.

The reading assessment portion of the session began with a picture-letter matching task. On each of 10 trials, the child was shown three pictures and one alphabetic symbol which began the name of only one of the objects pictured. The child was asked to name each picture and was supplied with the intended name if that name was not volunteered. The child was then asked to point to the picture that "went best" with the letter shown to the side of the pictures. (On a given trial, the alphabetic symbol shown represented a sound in the target picture only.) Experimenter 1 recorded each child's responses. Only those subjects who responded correctly on 8 out of the 10 trials advanced to the word identification part of the reading test.

The word identification test consisted of 20 one-syllable real and nonsense words printed on $3 \times 5$ in. cards. There were equal num- 
bers of real and nonsense words. During this test, Experimenter 1 held up the cards with the test items one at a time in random order. Experimenter 2 transcribed all readings of each word offered by the child. Each child received the one-syllable real and one-syllable nonsense word lists in this same order. If a child could not read any of the first four or five words in the real word list, the session was terminated. Before testing on the nonsense words, the child was told that he/she was going to see some "pretend" words made up by the experimenters and to say these aloud even though the words might sound silly.

\section{Results}

In pretraining, kindergartners reached the criterion of 10 consecutively correct associations of standards to puppets in 13.17 trials on average; the second graders met this criterion in 11.15 trials on average. During the test phase, the kindergartners correctly classified the standards on $92 \%$ of the trials; the second graders did so on $98 \%$ of the trials. These differences were not statistically significant.

Group classifications of test items. Each subject's number of correct classifications of test items was submitted to an analysis of variance for a 2 (grade) $\times 3$ (test item) $\times 2$ (stimulus set) mixed design. The analysis revealed a main effect of test item $[F(2,44)=9.98, p<$ $.001]$ and a reliable interaction between grade and test item $[F(2,44)=4.16, p<.025]$. Figure 1 shows the mean proportion of correct classifications (and the standard error of the mean) for the three test-item types at the two grade levels. Post hoc analyses (Tukey B, $\propto=.05$, critical difference in proportion correct $=.15$ ) revealed that the second graders performed equally well on all test-item types. Consistent with our expectations then, the second graders were well able to classify the bisyllabic utterances used in this experiment by single phoneme correspondences. The kindergartners' performance, unlike that of the second graders, did depend on test-item

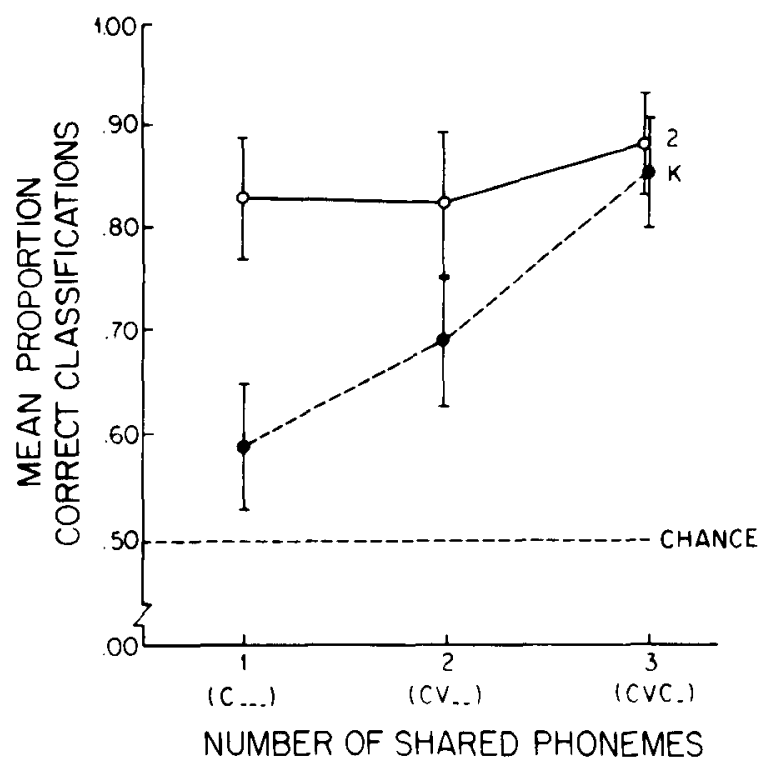

Figure 1. Group classification performance in Experiment 1. (Vertical bars indicate standard errors of the means.) type. Kindergartners classified the $\mathrm{CVC}_{\text {_ }}$ items more accurately than $\mathrm{CV}_{-}$or $\mathrm{C}$ _ items, but their performance on these last two types did not differ, indicating that the whole syllable correspondence between the $\mathrm{CV}$ _ items and the standards was not particularly salient to the younger children. Furthermore, these younger listeners classified the $\mathrm{C}_{\text {_ }}$ and $\mathrm{CV}_{\text {_ }}$, but not the $\mathrm{CVC}_{-}$items less accurately than did the second graders.

Contrary to our expectations, then, the kindergartners did not classify the whole-syllable $\mathrm{CV}_{\text {_ }}$ items very accurately. Indeed, they did not classify these items much better than the single-phoneme $\left(\mathrm{C}_{\longrightarrow}\right)$ items; although there was a trend toward better performance on the $\mathrm{CV}_{\text {_ }}$ versus $\mathrm{C}$ _ items for the kindergartners, this comparison was not reliable. This null finding might be attributable to our modest sample size. However, kindergartners' performance for $\mathrm{CV}$ _ items was reliably worse than for $\mathrm{CVC}_{-}$items. Individual subjects' performances, presented below, also support the interpretation that the syllable was not particularly salient to the kindergartners in this task. Kindergartners only performed as well as the older children when the test item (CVC_.) was extremely similar overall to a standard - that is, when it was identical in three out of four of its constituents [in fact, both kindergartners and second graders performed as well on these items as they did for the standards in testing; $t(11)<1.00$ in each case]; they performed reliably more poorly than the older children both when the test item and standard shared a whole syllable and when they shared only the initial phoneme.

Individual patterns of performance. The patterns of individual performances are consistent with the results of the group analyses. A child was scored as having consistently classified each test-item type if he/she correctly classified items of that type on at least seven of the eight possible trials and then was placed in the inconsistent category or in one and only one of three consistent categories (initial phoneme, syllable, maximal similarity), since we wished to determine what the minimal basis for consistent classification by each subject might be. As can be seen in Table 2, many more second graders than kindergartners consistently classified items of all three types $\left[\chi^{2}(1)=8.70, p<.005\right]$, a pattern of performance consistent with the notion that older children are better able to attend to single-phoneme correspondences. As is evi-

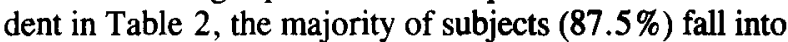
one of three categories: successful classification by initial consonant ( $\mathrm{C}_{\text {_ }}$ items plus other items), successful classification only of CVC _ items (those maximally similar to one standard), or inconsistent classification of all test-item types. In other words, very few subjects' pattern of performance fits that expected by the hypothesis that the syllable is a perceptually salient unit and thereby sufficient for correct classification.

Kindergartners' classification performance and reading ability. The kindergartners' classification performance was related to success on the letter-naming matching task (Pearson's $r=.82, p<.01$ ). Only 2 of the 
Table 2

Individual Patterns of Classification Performance in Experiment 1

\begin{tabular}{|c|c|c|c|c|}
\hline \multirow[b]{2}{*}{ Grade } & \multicolumn{4}{|c|}{ Classification } \\
\hline & $\begin{array}{c}\left.\begin{array}{c}\text { Initial Phoneme } \\
\left(\mathrm{C}_{-},\right.\end{array} \mathrm{CV}_{-}, \mathrm{CVC}_{-}\right) \\
\end{array}$ & $\begin{array}{c}\text { Syllable } \\
\left(\mathrm{CV}_{-}, \mathrm{CVC}_{-}\right)\end{array}$ & $\begin{array}{c}\text { Maximal Similarity } \\
\text { (CVC_) }\end{array}$ & Inconsisten \\
\hline $\mathbf{K}$ & 1 & 1 & 6 & 4 \\
\hline 2 & 8 & 2 & 1 & 1 \\
\hline Total & 9 & 3 & 7 & 5 \\
\hline
\end{tabular}

Note-Shown is the number of subjects fitting each classification category. $\mathrm{K}=$ Kindergartners; $2=$ Second graders.

kindergartners were able to read 5 or more of the 10 real words in the visual word identification task; 1 of these subjects correctly classified all test items, and the other correctly classified only the test items that shared a syllable with the standards. These 2 early readers, unlike their classmates, thus appeared to be sensitive to component phonemes in one case and component syllables in the other case.

\section{Discussion}

The surprising result of this experiment was that a shared syllable appeared to have no special status in either the younger or older children's comparisons of speech sounds. Note that the younger (and older) children's failure with the syllable-identity classifications was not due simply to a failure to do the task or to any simple attentional/memory problem. All the kindergartners were able to classify an identical test item with a standard, and $67 \%$ of the kindergartners correctly classified the test items that shared three of four constituent phonemes with a standard. These kindergartners, then, were clearly attending to the test items, and when similarity relations were maximal, they were able to correctly classify them. However, a shared syllable among test items and standards did not present a sufficiently strong relation for kindergartners to classify items easily and consistently. Experiment 2 was designed to replicate and further examine this surprising finding about the apparent nonsalience of syllable correspondences.

\section{EXPERIMENT 2}

In Experiment 2, we again asked children to classify two-syllable nonsense words. Table 3 shows a sample stimulus set and illustrates the structure of the four different test-item types used in the experiment. All four testitem types share two phonemes (one consonant and one vowel) with one standard and no phonemes with the second standard. The test-item types differ in which two constituent phonemes are shared with a given standard. Two of the test-item types $\left(\mathrm{C}_{1} \mathrm{~V}_{1}\right.$ and $\left.-\mathrm{C}_{2} \mathrm{~V}_{2}\right)$ share a whole syllable with one standard. If a whole-syllable correspondence is particularly salient for children, these two types should be classified correctly more often than the remaining two types; the two remaining types also share one consonant and one vowel with one standard, but these shared phonemes are in separate syllables.
This contrast between syllable versus nonsyllable correspondences is not the only possible one of interest. Some researchers in speech perception and language acquisition have maintained that the beginnings of words are particularly salient (e.g., Cole, 1973, 1981; Cole \& Jakimik, 1980; Marslen-Wilson \& Tyler, 1980; Marslen-Wilson \& Welsh, 1978; Slobin, 1973; Tyler \& Marslen-Wilson, 1982; see also Foss \& Blank, 1980; Grosjean, 1980; Salasoo \& Pisoni, 1985). It has also been proposed that the ends of words play a special role in the perception of spoken language (Cole \& Jakimik, 1980; Slobin, 1973). We can examine the relative importance of the position of correspondences by comparing performance when a phonemic correspondence is at the beginning of a test item to when it is not $\left(C_{1} V_{1}\right.$ and $C_{1}-V_{2}$ vs. $-V_{1} C_{2}$ and $-\mathrm{C}_{2} \mathrm{~V}_{2}$ items) and by comparing performance when there is a phonemic identity at the end of a test item to when there is not $\left(C_{1}-V_{2}\right.$ and $-C_{2} V_{2}$ vs. $C_{1} V_{1}$ and $-\mathrm{V}_{1} \mathrm{C}_{2}$ items).

In total, the four test-item types divide into three orthogonal comparisons, summarized in Table 4. The first comparison contrasts items sharing an entire syllable with the correct standard versus those sharing two phonemes that are parts of separate syllables. The second compari-

Table 3

Sample Stimulus Set from Experiment 2

\begin{tabular}{|c|c|c|}
\hline \multirow{2}{*}{$\begin{array}{l}\text { Test-Item } \\
\text { Type }\end{array}$} & \multicolumn{2}{|c|}{ Standards } \\
\hline & šona & lortu \\
\hline $\mathrm{C}_{1} \mathrm{~V}_{1}$ & $\begin{array}{l}\text { šogae } \\
\text { šobi }\end{array}$ & $\begin{array}{l}\text { lag gi } \\
\text { larbae }\end{array}$ \\
\hline$-\mathrm{C}_{2} \mathrm{~V}_{2}$ & $\begin{array}{l}\text { gina } \\
\text { bina }\end{array}$ & $\begin{array}{l}\text { bitu } \\
\text { gitu }\end{array}$ \\
\hline $\mathrm{C}_{1} \_\mathrm{V}_{2}$ & $\begin{array}{l}\text { šaega } \\
\text { šiba }\end{array}$ & $\begin{array}{l}\text { ligu } \\
\text { laebu }\end{array}$ \\
\hline$-\mathrm{V}_{1} \mathrm{C}_{2}$ & $\begin{array}{l}\text { bonae } \\
\text { goni }\end{array}$ & $\begin{array}{l}\text { gaxti } \\
\text { baxti }\end{array}$ \\
\hline
\end{tabular}

Table 4

Summary of Orthogonal Comparisons in Experiment 2

\begin{tabular}{llll}
\hline Comparison Type & \multicolumn{3}{c}{ Examples } \\
\hline Syllable & $\mathrm{C}_{1} \mathrm{~V}_{1}$ & vs. & $\mathrm{C}_{1}-\mathrm{V}_{2}$ \\
& $\mathrm{C}_{2} \mathrm{~V}_{2}$ & vs. & $-\mathrm{V}_{1} \mathrm{C}_{2}$ \\
Initial Consonant & $\mathrm{C}_{1} \mathrm{~V}_{1}$ & vs. & $\mathrm{C}_{2} \mathrm{~V}_{2}$ \\
& $\mathrm{C}_{1}-\mathrm{V}_{2}$ & vs. & $-\mathrm{V}_{1} \mathrm{C}_{2-}$ \\
Final Vowel & $-\mathrm{C}_{2} \mathrm{~V}_{2}$ & vs. & $\mathrm{C}_{1} \mathrm{~V}_{1--}$ \\
& $\mathrm{C}_{1--} \mathrm{V}_{2}$ & vs. & $-\mathrm{V}_{1} \mathrm{C}_{2}$ \\
\hline
\end{tabular}


son contrasts test items sharing an initial consonant with those items that differ from the standard in the initial consonant. The third comparison contrasts test items sharing a final vowel with the correct standard versus those items which differ from the correct standard in the final vowel. The question of interest is whether any of these structural aspects of the correspondence between test items and standards is perceptually more dominant than the others. Our primary concern, of course, is whether wholesyllable correspondences result in better performance than when the correspondences are not contained within one syllable.

\section{Method}

Subjects. Twelve kindergartners (mean age $=5$ years, 9 months; range $=5,3$ to 6,$0 ; 3$ males, 9 females) and 12 second graders (mean age $=8,2$; range $=7,11$ to 8,$7 ; 7$ males, 5 females), who were enrolled in an Indiana elementary school serving a middleclass population, participated in the experiment. All subjects met similar criteria as specified for Experiment 1, including 10 correct consecutive responses in training and $75 \%$ correct classifications of the standards in testing.

Stimuli and Design. Two sets of CV-CV stimuli were constructed from the consonant and vowel pools described in Experiment 1 . Each stimulus set consisted of four different test-item types; that is, a test item was related to one of the two standards or training items of the set in one of four possible ways: a test item was identical to one of the standards in (1) its initial syllable $\left(\mathrm{C}_{1} \mathrm{~V}_{1-\ldots}\right)$, (2) its second (or final) syllable $\left(-C_{2} V_{2}\right),(3)$ its initial and final phonemic segments $\left(C_{1} \ldots V_{2}\right)$, or (4) its two medial phonemes $\left(\mathrm{V}_{1} \mathrm{C}_{2}\right)$. The remainder of any given test item consisted of a combination of the items left in the consonant and vowel pools. Within each stimulus set, two different test items were related to either of the standards in one of the ways specified above (see Table 3).

Audiotapes of the two stimulus sets were prepared, and the intended CV-CV structure of the stimuli was confirmed by an adult listener in the same way as specified for Experiment 1 . All (100\%) of the listener's responses were consistent with the intended structure. The test items occurred twice within the test sequence of a tape in random order (i.e., 32 test trials), with the restriction that one of the training items intervened between every 4 presentations of a test stimulus. Thus, a test block consisted of 40 stimulus presentations. Subjects were randomly assigned to one of the stimulus sets, and the assignment of puppets to standards within a set was counterbalanced.

Procedure. The procedure was identical to that of Experiment 1.

\section{Results}

During pretraining, the kindergartners and second graders learned to associate the two standards to the two puppets equally rapidly; the mean number of trials to criterion was 10.9 for kindergartners and 10.1 for second graders. During testing, the kindergartners correctly classified the standards on $96 \%$ of the trials; the second graders performed perfectly. This difference was not statistically significant.

Group classification of test items. Each child's number of correct classifications of the four test-item types $\left(\mathrm{C}_{1} \mathrm{~V}_{1}-\mathrm{C}_{2} \mathrm{~V}_{2}, \mathrm{C}_{1}-\mathrm{V}_{2},-\mathrm{V}_{1} \mathrm{C}_{2}\right)$ was submitted to an analysis of variance for a 2 (age) $\times 4$ (test item) $\times$ 2 (stimulus set) mixed design. The analysis revealed main effects of age $[F(1,22)=8.78, p<.01]$ and test item
$[F(3,66)=11.58, p<.001]$ and a reliable interaction between age and test item $[F(3,66)=5.03, p<.005]$. Table 5 shows the mean proportion of correct classifications (and the standard error of the mean) for each of the four test-item types at the two grade levels. Post hoc comparisons (Tukey $\mathrm{B}, \propto=.05$, critical difference in proportion correct $=.16$ ) indicated that kindergartners and second graders performed equally well on the test items identical to a standard in their initial syllable $\left(C_{1} V_{1-}\right)$ and equally poorly on the test items identical to a standard in the medial vowel and consonant $\left(-V_{1} C_{2-}\right)$. However, second graders correctly classified test items sharing the initial consonant and final vowel with a standard $\left(C_{1} \ldots V_{2}\right)$ and those sharing the final syllable $\left(-C_{2} V_{2}\right)$ with a standard significantly more often than did kindergartners.

Two within-subject contrasts were also reliable in the second graders' data: $\mathrm{C}_{1} \mathrm{~V}_{1}$ - versus $-\mathrm{V}_{1} \mathrm{C}_{2}$ and $C_{1}-V_{2}$ versus $\_V_{1} C_{2-}$. Second graders' performance was high both when the test items shared the initial syllable with a standard and when it shared the initial consonant and final vowel with a standard. Performance was lowest when the test item shared only the medial vowel and consonant with a standard. In the kindergartners' data, only the $\mathrm{C}_{1} \mathrm{~V}_{1}$ - versus $\mathrm{V}_{1} \mathrm{C}_{2}$ contrast was reliable. That is, these subjects classified correctly most often when a test item shared an initial syllable with a standard and least well when the test item did not share an initial syllable, initial consonant, or final vowel with a standard. However, kindergartners' classifications of $C_{1} V_{1}$ items tended to be more accurate than their classifications of $\mathrm{C}_{2} \mathrm{~V}_{2}$ items.

The kindergartners' and second graders' high levels of performance on test items sharing an initial syllable with a standard could be due to either the syllable correspondence or the (initial) position of the correspondence or both factors. The outcomes of the three planned orthogonal comparisons of performance on the test-item types suggest that whole-syllable correspondences are not the overriding factor. Instead, position appears to be more critical. (For all paired comparisons, $p<.05$ and the critical value for a difference in proportion correct is .11.)

Table 5

Mean Proportion Correct and Standard Errors of the Means for the Four Test-Item Types in Experiment 2

\begin{tabular}{|c|c|c|c|c|}
\hline \multirow{2}{*}{$\begin{array}{c}\text { Test-Item } \\
\text { Type }\end{array}$} & \multicolumn{2}{|c|}{ Kindergarten } & \multicolumn{2}{|c|}{ Second Grade } \\
\hline & Mean & SEM & Mean & SEM \\
\hline$C_{1} V_{1-}$ & .84 & .04 & .92 & .03 \\
\hline$-C_{2} V_{2}$ & .68 & .06 & .86 & .07 \\
\hline$C_{1}-V_{2}$ & .75 & .07 & .97 & .02 \\
\hline$-\mathrm{V}_{1} \mathrm{C}_{2}$ & .66 & .03 & .70 & .05 \\
\hline
\end{tabular}

Comparison

Syllable/Not S

Initial Consonant/Not IC

Final Vowel/Not FV

$.76 / .70$
$.80 / .67$

$.80 / .84$

$.72 / 74 * 92 / .81 *$

Note-SEM $=$ Standard error of mean. Shown at the bottom are the combined proportions entering into the planned comparisons. ${ }^{*} p<.05$ 
At neither age level was the contrast between the two item types sharing a whole syllable and the two item types not sharing a syllable with the correct standards reliable (see Table 5). Thus, a syllable identity per se does not appear to be particularly beneficial to performance. Again it is possible that this failure to observe a reliable difference is attributable to a lack of power. However, the design was sensitive to other within- and between-subjects differences. In addition, the performance of individual subjects, reported below, once more supports the conclusion that syllable identities are not very salient. Both kindergartners and second graders did correctly classify items sharing their initial consonant with a standard more often than items that did not (see Table 5). A correspondence at the beginning of a speech sound - whether a whole syllable or simply the initial consonant - is noticed more by young children than are other noninitial correspondences. Yet, kindergartners' performance on items sharing an initial syllable or consonant with one of the standards was not, in contrast to that of second graders', as good as their performance for the standards themselves in testing [in a comparison of subjects' best performance for either $C_{1} V_{1}$ or $C_{1}-V_{2}$ items vs. performance for the standards, $t(11)=2.77, p<.01$, for a one-tailed test, $t(11)<1.00$, for kindergartners and second graders, respectively]. Finally, the second graders, but not the kindergartners, correctly classified test items that shared the final vowel with the correct standard more often than they did items that did not (see Table 5). Therefore, correspondences at the ends of speech sounds also appear to be noticed by at least older children.

Taken together, these results suggest a developmental trend in those aspects of the internal structure of speech sounds that control their perceived similarity. Attention to the beginnings of utterances is developmentally prior to attention to the ends of utterances (cf. Williams, Blumberg, \& Williams, 1970). In addition, the position of correspondences apparently plays a stronger role in controlling performance than does the unit of correspondence (phoneme vs. syllable). This interpretation conflicts with the hypothesis that the young child's perception of speech is structured by syllable units, but is consistent with the results of Experiment 1.

Individual patterns of performance. The patterns of individual performances further support the notion that whole syllable correspondences have no special status in the perceived similarity of speech sounds for young children. Table 6 shows the number of children correctly classifying each of the four types of test items on at least seven of the eight trials for that type. (Unlike in Experiment 1, then, a given individual may fall into more than one of the item categories, which are not ordered in terms of increasing amount of segmental overlap with the standards.) Note that the number of children succeeding is highest on $C_{1} V_{1}$ and $C_{1} \ldots V_{2}$ items, the two item types that share their initial consonant with one of the standards. The high level of performance on $C_{1} V_{1}$ items could be attributed to the syllable correspondence in initial po-
Table 6

Individual Patterns of Classification Performance in Experiment 2

\begin{tabular}{ccccc}
\hline & \multicolumn{4}{c}{ Consistent Classifications } \\
\cline { 2 - 5 } Grade & $\mathrm{C}_{1} \mathrm{~V}_{1}$ & $-\mathrm{C}_{2} \mathrm{~V}_{2}$ & $\mathrm{C}_{1--} \mathrm{V}_{2}$ & $-\mathrm{V}_{1} \mathrm{C}_{2}$ \\
\hline $\mathrm{K}$ & 10 & 2 & 5 & 3 \\
2 & 10 & 9 & 12 & 3 \\
Total & 20 & 11 & 17 & 6 \\
\hline
\end{tabular}

Note-Shown is the number of subjects who consistently classified the test-item types.

sition. However, relative to performance on items with initial syllable correspondences, children succeeded on items containing a correspondence in only the initial consonant and final vowel $\left(\mathrm{C}_{1}-\mathrm{V}_{2}\right)$ just as frequently $\left[\chi^{2}(1)<1.00\right]$, whereas markedly fewer children succeeded with items sharing a final syllable $\left(-\mathrm{C}_{2} \mathrm{~V}_{2}\right)$ with the correct standard $\left[\chi^{2}(1)=10.39, p<.005\right]$. The position of a correspondence between two speech sounds thus appears a more critical determinant of children's use of that correspondence than does the unit of correspondence.

Kindergartners' classification performance and reading ability. The kindergartners' performance on the classification task was not correlated with their ability to match letters to pictures (Pearson's $r=-.07$ ). This result is not surprising, since, in this experiment, all test items shared two phonemes with one of the standards and thus were relatively similar overall to that standard. None of the kindergartners in this experiment was able to read any of the words in the word identification task.

\section{Discussion}

The results of this experiment replicate those of Experiment 1 by showing, again, that young children are not substantially better at classifying speech sounds by corresponding syllables than by corresponding phonemes. The results do suggest that some aspects of the internal structural relations among speech sounds matter to young children, namely the position of correspondence.

\section{GENERAL DISCUSSION}

Past research indicates that younger children have difficulty in selectively attending to single phonemes; instead, they tend to compare speech sounds more globally than do older children (e.g., I. Y. Liberman et al., 1974; Treiman \& Baron, 1981). Our results in Experiment 1 are consistent with these previous findings. The kindergartners did not classify together speech sounds that shared a single initial phoneme, but did classify with high accuracy items that shared three of four phonemes. In contrast, second graders accurately classified whether items shared a single initial phoneme or three phonemes. Thus, as do previous findings, our results suggest an age-related increase in attention to single-phoneme relations. A single (initial)-phoneme correspondence is sufficient for older children to classify together two speech sounds, but younger children require more similarity across whole sounds 
to classify them together. Consistent with this notion is the fact that younger children's performance appears to have been better overall in Experiment 2 than in Experiment 1; in Experiment 2, all test items shared two of their four phonemic components with one of the standards.

Our results, however, do not support the notion that young children are more likely than older children to compare speech sounds via the larger syllabic unit. Younger children's more global perceptions cannot be equated simply with syllable perception. In neither Experiment 1 nor Experiment 2 did younger children perform markedly better when test item and standard shared a whole syllable. Furthermore, our results suggest no special status for syllables in older children's comparisons of speech sounds. Second graders classified no more correctly when test item and standard shared a two-phoneme syllable than when they shared a single initial phoneme (Experiment 1) or when they shared certain combinations of two phonemes that did not form one syllable (Experiment 2).

Our failure to observe any special status of the syllable does not mean that the structure of the correspondences between sounds is unimportant. The developmental trend is not simply from correct classifications with many phonemic correspondences to correct classifications given a single corresponding phoneme. Rather, our results suggest that position, as well as the number, of shared constituents (either phonemes or syllables) matter. There appears to be a developmental trend whereby (1) attention to the beginnings of sounds emerges prior to attention to the ends of sounds and (2) attention to final correspondences is stronger than attention to whole syllables. In brief, in the present task at least, it did not matter greatly whether corresponding phonemes formed a syllable unit or not, but it did matter where the correspondences were located.

Our finding concerning the lack of any special status of the syllable in our classification task is certainly troublesome for simple hypotheses about the greater salience of syllables relative to phonemes for younger children. It also conflicts with other results suggesting the greater accessibility of the syllable in comparison to the phoneme. Perhaps the principle of "salience of syllables" needs to be restricted to certain sorts of tasks (see Rozin \& Gleitman, 1977, for further discussion). More specifically, the discrepancy between our results and those of previous studies may be due to differences in the level and kind of processing entailed in our classification task and the more explicit segmentation tasks that have been employed in prior studies.

Our classification task differs in a perhaps very important way from the kinds of tasks that have suggested the developmental primacy of the syllable. Our task only required the child to decide which of two sounds (or standards) a test item was most like. The child was not required to indicate how two sounds that were classified together were alike, nor was he/she actually required in any way to adopt a particular strategy to make a classification. In contrast, previous studies suggesting superior performance with syllables versus phonemes have in- volved the explicit manipulation of segments, requiring, for example, that the child count the segments (e.g., Treiman \& Baron, 1981) or isolate, then rearrange or delete, one or more segments (e.g., Bruce, 1964; Calfee et al., 1972; Rosner \& Simon, 1971; Savin, 1972; Stanovich et al., 1984). Such studies, thus, have focused on the child's conscious attention to phonemes and syllables. Perhaps, then, syllables are "special" for children, but only at the level at which they must be actively manipulated. Syllables may have no special status at the level at which the perceptual similarity of two speech sounds is calculated.

The kind of task which our classification task may more closely resemble is word recognition. Our task is like word recognition in that it requires a perceptual similarity match between a test item and items in memory (the standards), rather than conscious attention to the underlying structure that determines similarity. Analogously, when the child hears a word, such as telephone, he or she must decide whether it matches most closely the representations of telephone, elephant, or so forth in memory. Our particular pattern of findings is similar to the results obtained in word recognition tasks. Specifically, our finding concerning the importance of the number and position of correspondences to the perceived similarity of speech sounds is in keeping with recent accounts of the nature of auditory word recognition (e.g., Marslen-Wilson \& Tyler, 1980; Marslen-Wilson \& Welsh, 1978; Tyler \& Marslen-Wilson, 1982; see also Cole \& Jakimik, 1980; Foss \& Blank, 1980; Grosjean, 1980; Salasoo \& Pisoni, 1985). According to these proposals, the acoustic-phonetic information corresponding to the beginnings of words plays a particularly critical role in the word recognition process for adults. Cole (1981) has offered a similar characterization of spoken word recognition and lexical access in young children. In support of this is the finding that young children, like adults, are more accurate at detecting mispronunciations in word-initial than in word-final position. Thus, the beginnings of words appear to be heavily weighted in the recognition process, and less attention is devoted to the analysis of subsequent acoustic-phonetic information. However, this weighting may be one that continues to develop with language experience (specifically, with vocabulary acquisition), and for children, more so than for adults, its invocation may depend on the nature of stimulus and task variables. For example, the extent of reliance on word-initial information for recognition may be influenced more in the young child than in the adult by the availability of contextual constraints (see Cole \& Perfetti, 1980 Walley, 1984). To the extent that an actual lexical (decision) component was not involved in the present classification task, the attention to initial correspondences that we observed might reflect the sort of basic perceptual (vs. more cognitive) processes that are brought to bear in word recognition.

The salience of initial correspondences may also serve as part of the foundation for the implementation of the sort of "operating principles" proposed by Slobin (1973) 
as characterizing language acquisition strategies. One procedure for discovering the formal and functional relations between linguistic elements is, Slobin maintains, "Pay attention to the order of words and morphemes." Another is "Pay attention to the ends of words." Cole and Jakimik (1980) have also suggested that the isolation of a given word in fluent speech, and thus of its final phonemic segments, contributes to the identification of subsequent words. However, as our results indicated, attention to the final elements of isolated spoken utterances may emerge later in development than attention to initial correspondences, at least at the level of perception tapped in the classification task. In any event, the findings reported here are generally in keeping with several proposals concerning the acquisition of spoken vocabulary. Moreover, they may be indicative of how the comparison operations used to match encoded items with memory representations change with development. Thus, they are relevant to the development of spoken word recognition and lexical access.

In conclusion, young children's perception of speech sounds can be viewed as more global than that of older children in the sense that the perceived similarity of speech sounds depends on a greater number of shared constituents across the whole sound. However, it is not the case that this trend is from the perception of speech in terms of syllable units to perception in terms of phoneme units. Syllables may be more accessible than phonemes, and, in some tasks, the syllable may be the unit that controls younger children's performance. But the syllable is not always the organizing unit for children and it is not always more controlling of performance than is the phoneme. We speculate that syllables may be special at the level of consciousness, but that at the level of perceptual similarity, the level at which a sound contacts a representation in memory, the syllable may play no special role.

\section{REFERENCES}

Asuin, R. N., Pisonı, D. B., \& Jusczyk, P. W. (1983). Auditory development and speech perception in infancy. In $\mathbf{M}$. Haith \& $\mathbf{J}$. Campos (Eds.), Infancy and developmental psychobiology, Vol. 2 of P. H. Mussen's (Series Ed.), Handbook of child psychology. New York: Wiley.

BERTONCINI, J., \& MEHLER, J. (1981). Syllables as units in infant speech perception. Infant Behavior \& Development, 4, 247-260.

BRUCE, D. J. (1964). The analysis of word sounds by young children. British Journal of Educational Psychology, 34, 158-169.

Calfee, R. C., Chapman, R. S., \& Venezky, R. (1972). How a child needs to think to learn to read. In L. W. Gregg (Ed.), Cognition in learning and memory. New York: Wiley.

COLE, R. A. (1973). Listening for mispronunciations: A measure of what we hear during speech. Perception \& Psychophysics, 11, 153-156.

COLE, R. A. (1981). Perception of fluent speech by children and adults. Annals of the New York Academy of Sciences, 379, 92-109.

COLE, R. A., \& JAKIMIK, J. S. (1980). A model of speech perception. In R. A. Cole (Ed.), Perception and production of fluent speech. Hillsdale, NJ: Erlbaum.

Cole, R. A., \& Perfetti, C. A. (1980). Listening for mispronunciations in a children's story: The use of context by children and adults. Journal of Verbal Learning \& Verbal Behavior, 19, 297-315.
Elkonin, D. B. (1973). USSR. In J. Downing (Ed.), Comparative reading. New York: Macmilian.

Foss, D. J., Blank, M. A. (1980). Identifying the speech codes. Cognitive Psychology, 12, 1-31.

Foss, D. J., \& SwINNEY, D. A. (1973). On the psychological reality of the phoneme. Perception, identification, and consciousness. Journal of Verbal Learning \& Verbal Behavior, 12, 246-257.

Gleitman, L. R., RozIN, P. (1977). The structure and acquisition of reading: I. Relations between orthographies and the structure of language. In A. S. Reber \& D. L. Scarborough (Eds.), Toward a psychology of reading. Hillsdale, NJ: Erlbaum.

Grosjean, F. (1980). Spoken word recognition processes and the gating paradigm. Perception \& Psychophysics, 28, 267-283.

JusCZYK, P. W. (1977). Rhymes and reasons: Some aspects of the child's appreciation of poetic form. Developmental Psychology, 13, 599-607.

JUSCZYK, P. W. (1982). Auditory versus phonetic coding of speech signals during infancy. In J. Mehler, E. C. T. Walker, \& M. Garrett (Eds.), Perspectives on mental representation: Experimental and theoretical studies of cognitive processes and capacities. Hillsdale, NJ: Erlbaum. JusCZYK, P. W. (1983). On characterizing the development of speech perception. In J. Mehler \& R. Fox (Eds.), Neonate cognition: Beyond the blooming, buzzing confusion. Hillsdale, NJ: Erlbaum.

Liberman, A. M., CoOper, F. S., Shankweiler, D., \& StuddertKennedy, M. (1967). Perception of the speech code. Psychological Review, 74, 431-435.

Liberman, I. Y., Shankweiler, D., Fischer, F. W., \& Carter, B. (1974). Explicit syllable and phoneme segmentation in the young child. Journal of Experimental Child Psychology, 18, 201-212.

Liberman, I. Y., Shankweiler, D., Liberman, A. M., Fowler, C., \& FisCHER, F. W. (1977). Phonetic segmentation and recoding in the beginning reader. In A. S. Reber \& D. L. Scarborough (Eds.), Toward a psychology of reading. Hillsdale, NJ: Erlbaum.

Marslen-Wilson, W. D., \& TYler, L. K. (1980). The temporal structure of spoken language understanding. Cognition, 8, 1-71.

Marslen-Wilson, W. D., \& Welsh, A. (1978). Processing interactions and lexical access during word recognition in continuous speech. Cognitive Psychology, 10, 29-63.

Mehler, J., Dommergues, J. Y., Frauenfelder, U., \& Segui, J. (1981). The syllable's role in speech segmentation. Journal of Verbal Learning \& Verbal Behavior, 20, 298-305.

ROSNER, J., \& Simon, D. (1971). The Auditory Analysis Test: An initial report. Journal of Leaming Disabilities, 4, 384-392.

Rozin, P., Bressman, B., \& TAFT, M. (1974). Do children understand the basic relationship between speech and writing? The mowmotorcycle test. Journal of Reading Behavior, 6, 327-334.

Rozin, P., \& Gleitman, L. R. (1977). The structure and acquisition of reading: II. The reading process and the acquisition of the alphabetic principle. In A. S. Reber \& D. L. Scarborough (Eds.), Toward a psychology of reading. Hillsdale, $\mathrm{NJ}$ : Eribaum.

SALASOO, A., PISONI, D. B. (1985). Interaction of knowledge sources in spoken word identification. Journal of Memory \& Language, 24, 210-231.

SAvin, H. B. (1972). What the child knows about speech when he starts to learn to read. In J. F. Kavanagh \& I. G. Mattingly (Eds.), Language by ear and by eye: The relationship between speech and reading. Cambridge: MIT Press.

SAVIN, H. B., BeVER, T. G. (1970). The nonperceptual reality of the phoneme. Journal of Verbal Learning \& Verbal Behavior, 9 , 295-302.

SINGH, S., \& Woods, D. R. (1971). Perceptual structure of 12 American English vowels. Journal of the Acoustical Society of America, 49, 1861-1866.

Singh, S., Woods, D. R. , \& Becker, G. M. (1972). Perceptual structure of 22 prevocalic English consonants. Journal of the Acoustical Society of America, 52, 1698-1713.

SLobin, D. I. (1973). Cognitive prerequisites for the development of grammar. In C. A. Ferguson \& D. I. Slobin (Eds.), Studies of child language development. New York: Holt, Rinehart \& Winston.

Stanovich, K. E., Cunningham, A. E., \& Cramer, B. B. (1984). Assessing phonological awareness of kindergarten children: Issues 
of task comparability. Journal of Experimental Child Psychology, 38 , 175-190.

Treiman, R. (1980). The phonemic analysis ability of preschool children. Unpublished doctoral dissertation, University of Pennsylvania, Philadelphia.

Treiman, R., \& Baron, J. (1981). Segmental analysis ability: Development and relation to reading ability. In T. G. Waller \& G. E. MacKinnon (Eds.), Reading research: Advances in theory and practice (Vol. 3). New York: Academic Press.

Treiman, R., \& Breaux, A. M. (1982). Common phoneme and overall similarity relations among spoken syllables: Their use by children and adults. Journal of Psycholinguistic Research, 11, 581-610.

Tyler, L. K., \& MARSLEN-WILSON, W. D. (1982). Speech comprehension processes. In J. Mehler, E. C. T. Walker, \& M. Garrett (Eds.), Perspectives on mental representation: Experimental and theoretical studies of cognitive processes and capacities. Hillsdale, NJ: Erlbaum.
WALL.EY, A. C. (1984). Developmental differences in spoken word identification. Unpublished doctoral dissertation, Indiana University, Bloomington

WALley, A. C., Smith, L. B., \& JusCzyK, P. W. (1980, September). Classification of $C V$ syllables by readers and prereaders. Paper presented at the 88th Annual Convention of the American Psychological Association, Montreal, Canada.

Williams, J. P., Blumberg, E. L., \& Williams, D. V. (1970). Cues used in visual word recognition. Journal of Educational Psychology, 61, 310-315

(Manuscript received April 9, 1985; revision accepted for publication January $6,1986$.

\section{ANNOUNCEMENT}

\section{1th Annual Conference on Language Development October 17, 18, and 19, 1986}

The Boston University School of Education invites papers for the 11th Annual Conference on Language Development, to be held on October 17, 18, and 19, 1986.

Papers on the topics of first and second language acquisition, bilingualism, language disorders, writing, literacy, narratives, ASL and sign language, neurolinguistics, sociolinguistics, theoretical language acquisition, and universal grammar will be considered for presentation at the conference. The deadline for submission of abstracts is June 1, 1986. This year's keynote speaker is Noam Chomsky from the Massachusetts Institute of Technology.

For more information write: Language Development Conference, School of Education, Boston University, Boston, MA 02215. 